\title{
Genetic Diversity of Potato Cultivars for Nitrogen Use Efficiency Under Contrasting Nitrogen Regimes
}

\author{
Baye Berihun Getahun ${ }^{1,2}$ (D) Molla Mekonen Kassie ${ }^{2}$. \\ Richard G. F. Visser ${ }^{1}$. C. Gerard van der Linden ${ }^{1}$
}

Received: 3 April 2019 / Accepted: 27 August 2019/

Published online: 14 October 2019

(C) The Author(s) 2019

\begin{abstract}
Developing cultivars that use nitrogen more efficiently is a sustainable strategy for reducing nitrogen use in crop production. To assess the genetic diversity for nitrogen use efficiency (NUE) and related traits in potato, a total of 97 (88 for the WesternEuropean market and 9 Ethiopian) cultivars were evaluated at two nitrogen levels (40 kg/ha and $120 \mathrm{~kg} / \mathrm{ha}$ ) for 24 quantitative traits in Debre-Tabor and Injibara (Ethiopia) in the 2013 main rainy season (June to September). Highly significant variation was found among genotypes for almost all measured traits. Plant height, NUE, tuber yield, and yield-related traits and model parameters for canopy development (maximum canopy covers area under the canopy curve) were significantly affected by $\mathrm{N}$ levels across locations. Dutch cultivars had more rapid initial canopy development and matured earlier than the Ethiopian cultivars at both $\mathrm{N}$ levels and locations. A hierarchical cluster analysis grouped the cultivars in 9 and 11 genetically distinct classes at low and high $\mathrm{N}$, respectively. The genetic component accounted for a large portion of the phenotypic variation for plant height, tuber number per plant, average tuber weight, and NUE under both $\mathrm{N}$ regimes, as indicated by a high heritability. Strong phenotypic correlations were observed between NUE and tuber number per plant, days to maturity, tuber dry matter \%, maximum canopy cover, and area under the canopy curve under both low and high $\mathrm{N}$ conditions. The result is indicative to set the best parental line selection criteria for crossing purpose and utilize the cultivars for further potato NUE breeding programmes.
\end{abstract}

Keywords Dutch potato cultivars $\cdot$ Ethiopian potato cultivars $\cdot$ Genetic diversity $\cdot$ Nitrogen use efficiency $\cdot$ Path coefficient analysis

Electronic supplementary material The online version of this article (https://doi.org/10.1007/s11540-01909439-8) contains supplementary material, which is available to authorized users.

C. Gerard van der Linden gerard.vanderlinden@wur.nl

Extended author information available on the last page of the article 


\section{Introduction}

Potato is the number 1 non-grain food crop in the world with an important contribution to the diets and livelihoods of millions of people globally. It is a well-recognized crop by the United Nations (UN) as food staple contributing to the Millennium Development Goals (MDG) for its potential to reduce poverty and improve food security (Bradshaw 2009). However, the optimal productivity of the crop is highly dependent on the nitrogen fertilizer level applied and/or available in the soil. Studies on the fertilizer price revealed that while global fertilizer prices have fallen in real terms, the trend has not been reflected in Sub-Saharan African countries. Reports on the cost of fertilizer indicated that fertilizer costs in Sub-Saharan Africa were at least four times more expensive than they were in Europe (https://gro-intelligence.com/insights/articles/fertilizers-in-sub-saharan-africa).

Thus, with high $\mathrm{N}$ fertilizer prices, the return of $\mathrm{N}$ input is low due to low uptake and utilization efficiency of the crop. The high costs and low returns of fertilizer use particularly burdens smallholder farmers in developing countries and force them to grow their crop under suboptimal N supply (Lafitte and Edmeades 1994).

Application of surplus nitrogen beyond the utilization capacity of the crop is affordable in high input agriculture and maximizes yield, but leads to nitrate pollution of ground water (Bertin and Gallais 2001). In developed countries, 50-70\% of the nitrogen provided to the soil for crop production is lost (Hodge et al. 2000). Most commercial potato cultivars are grown with high $\mathrm{N}$ fertilizer levels combined with irrigation, resulting in high reduction of nitrogen utilization efficiency (Zebarth et al. 2004a), highly contributing to N leaching and ground water contamination (Hill 1986; Richards et al. 1990). Significant emissions of nitrous oxide (a greenhouse gas) were also measured from potato fields (Flessa et al. 2002). Collectively, this makes a compelling case for improving $\mathrm{N}$ fertilizer use in agricultural crops like potato in developed as well as developing countries. To avoid nitrate pollution and to retain a sufficient profit margin, cultivars that are tolerant to low levels of nitrogen input are desirable (Bänzinger and Cooper 2001). Nitrogen use efficiency (NUE) is typically calculated as the yield per unit of $\mathrm{N}$ resource available to the plant (Moll et al. 1982). However, the method of NUE determination depends on the crop species and the objective of the study. In our case, NUE was determined as the tuber dry matter production, or dry weight of the tuber, per unit of $\mathrm{N}$ supplied (agronomic NUE).

The first step in improving potato for nitrogen use efficiency involves identification of crop plants that show exploitable variation for nitrogen use efficiency and related traits. Knowledge about the level of genetic diversity can aid with the introgression of desirable genes from diverse genepools into the available germplasm (Thompson and Nelson 1998). A better understanding of the genetic diversity, the different physiological processes involved and the underlying genetic relationships in plants grown under low and high $\mathrm{N}$ input regimes will help to choose the best starting material and traits for selection in breeding programmes targeting nitrogen use efficiency (NUE).

Significant variation in biomass partitioning and $\mathrm{N}$ uptake efficiency in low and high $\mathrm{N}$ environments was observed among potato cultivars, hybrids and wild species (Errebhi et al. 1999). Differences in NUE under high and low $\mathrm{N}$ input regimes were shown to be strongly associated with maturity type (Tiemens-Hulscher et al. 2012). Late maturing potato cultivars recorded higher NUE values than early maturing ones (Zebarth et al. 2004a; Ospina et al. 2014). This may be that the late maturing cultivars 
have higher area under the canopy curve (AUC); consequently, they have long period of light interception which is closely related with high total dry matter accumulation in the tuber which leads high nitrogen use efficiency. However, the genetic basis of NUE in potato is still poorly understood. The study of genetic diversity for NUE and related traits in easily accessible genotypes for breeding, like commercial cultivars, will be a first step to utilization of this diversity in NUE breeding programmes.

Genetic parameters and trait associations are helpful tools in genetic diversity studies, providing information about the expected response of different traits to selection that can be used to develop an optimal breeding strategy (Gopal 1999). In potato, many authors reported medium to high genetic parameter estimates for traits that may contribute to NUE. Moderate genotypic coefficient of variation (GCV) and high phenotypic coefficient of variation (PCV) values were reported for plant height, leaf area, tuber specific gravity, and tuber dry matter (Desai and Jaiminis 1997; Regassa and Basavaraj 2005). These high genetic parameter estimates and strong association of these traits with NUE indicate the importance of these traits for the indirect selection of nitrogen use efficient potato cultivars. High heritability combined with high genetic advance was also recorded for tuber yield per plant, tuber number per plant and average tuber weight (Regassa and Basavaraj 2005). However, genetic parameter estimates may vary from population to population as well as from environment to environment. Consequently, one should consider the population represented in the experiment and the environmental condition in which the experiment was conducted in when estimating genetic parameters (Dudley and Moll 1969; Nyquist 1991). Information on the genetic parameters of potato NUE and related agronomic and physiological traits both under low and high $\mathrm{N}$ growth conditions is vital for NUE improvement in potato. Similarly, the relationship of NUE with other physiological and agronomic traits is important for designing an effective breeding programme. So far, information on the genetic parameters of different agronomic and physiological traits involved in NUE and the underlying genetic relationships of these traits in potatoes is limited.

The objectives of this study were (i) to assess the extent and pattern of genetic diversity of Western potato cultivars compared to Ethiopian cultivars and (ii) to estimate genetic parameters and associations among desired traits that affect NUE of potato under low and high $\mathrm{N}$ availability.

\section{Materials and Methods}

\section{Plant Materials}

Potato tubers of 88 cultivars for the North-Western European market (here referred to as "Dutch") and breeding lines provided by HZPC Holland BV and nine Ethiopian cultivars were used in the experiment. The Dutch cultivars are common cultivars in the European potato market, used for different purposes. From the Ethiopian set, Agerie and Ater-Ababa are traditional cultivars that are relatively tolerant to most biotic as well as abiotic stresses. Other Ethiopian cultivars originated from the International Potato Center (CIP) and were released by different research centres in Ethiopia for their late blight resistance, tuber yield and wide adaptability in different parts of the country. See Supplementary Table 1 for a full list of the used cultivars. 


\section{Field Trials and Experimental Design}

The experiment was conducted at two different sites in North-western Ethiopia: Injibara and Debre-Tabor, which represent the major potato-growing areas in this part of the country. Injibara is located at $10.85^{\circ} \mathrm{N}$ latitude and $36.80^{\circ} \mathrm{E}$ longitude. The area receives about $2300 \mathrm{~mm}$ average rainfall per year with minimum (night) $8^{\circ} \mathrm{C}$ and maximum (day) $22^{\circ} \mathrm{C}$ average temperature. The soil at the Injibara site is Acrisol with a pH of 4.8 , and so is acidic. This soil acidity normally originates from the high amount of rainfall in the area, which is associated with heavy leaching of the top soil nutrients. Debre-Tabor is situated at an elevation of 2650 masl $\left(11.89^{\circ} \mathrm{N}\right.$ latitude and $38.04^{\circ} \mathrm{E}$ longitude). The average minimum (night) and maximum (day) temperature is $12{ }^{\circ} \mathrm{C}$ and $23{ }^{\circ} \mathrm{C}$, respectively, with average rainfall of $1500 \mathrm{~mm}$ per year. The soil at the Debre-Tabor site is Luvisol, and also acidic with $\mathrm{pH}$ 5.2. The experiment was laid out in a split-plot arrangement with two replications, where the main plots were allocated to the low and high $\mathrm{N}$ rates $(40 \mathrm{~kg} / \mathrm{ha}$, and $120 \mathrm{~kg} / \mathrm{ha})$ and the sub-plots to the genotypes. The low N (40 kg/ha) represents the amount most Ethiopian poor farmers apply to their potato crop while $120 \mathrm{~kg} / \mathrm{ha}$ as high $\mathrm{N}$ is above the recommended rate (the economically feasible recommended rate of $\mathrm{N}$ fertilizer is $80 \mathrm{~kg} / \mathrm{ha}$ ) in the area. Each subplot was planted on June 7 and 21, 2013 at Injibara and DebreTabor, respectively, in a single row consisting of 10 tubers, planted at a recommended inter- and intra-row spacing of $0.75 \mathrm{~m}$ and $0.30 \mathrm{~m}$, respectively, and each subplot was bordered by a reference potato cultivar. Pest and disease management, weeding and ridging and other cultivations were carried out as recommended and when required. The general chemical properties of the soil in the testing sites are presented in Table 1. Phosphorus and nitrogen sources were from the soil as well as from externally applied fertilizer. To determine the available nitrogen in the soil, composite soil samples were collected using a core sampling method at five locations at $0-20 \mathrm{~cm}$ and $20-40 \mathrm{~cm}$ depth from each of the experimental sites before planting and the available residual nitrogen in the form of $\mathrm{NO}_{3}{ }^{-}$and $\mathrm{NH}_{4}{ }^{+}$was extracted using a $\mathrm{KCl}$ extraction method. A total of 15 and $12 \mathrm{~kg} / \mathrm{ha} \mathrm{N}$ were recorded at Injibara and Debre-Tabor, respectively. The total amounts of $\mathrm{N}$ (40 and $120 \mathrm{~kg} / \mathrm{ha}$ ) were achieved by adding $\mathrm{N}$ to the soil in the form of urea and di-ammonium phosphate (DAP). Phosphorus fertilizer was applied following the recommendation for the area $\left(69 \mathrm{~kg} / \mathrm{ha} \mathrm{P}_{2} \mathrm{O}_{5}\right)$ in the form of DAP and tri-super phosphate (TSP). The whole $\mathrm{P}$ source was applied at planting while $\mathrm{N}$ application was split in two: a week after emergence and at early flowering.

\section{Trait Measurements}

The traits were measured similarly at the two experimental locations (Debre-Tabor and Injibara). Days to emergence (DTE) was the number of days from planting till 50\% of the plants emerged; it was assessed daily until all the plots had more than $50 \%$ emergence. Plant height $(\mathrm{PH})$ was measured as the distance in $\mathrm{cm}$ from the soil surface to the top of the canopy when $50 \%$ of the genotypes were flowering. Stem number per plant (SNPP) was the number of stems of a genotype counted just before the plants declined. Chlorophyll content (CC) was measured in leaves from the lower (LCC) and upper part (UCC) of two middle plants in a row and two leaves of each plant at each point (lower and upper) using SPAD-502 chlorophyll meter (Minolta Co., Ltd. Japan) when $50 \%$ of the genotypes were flowering. 


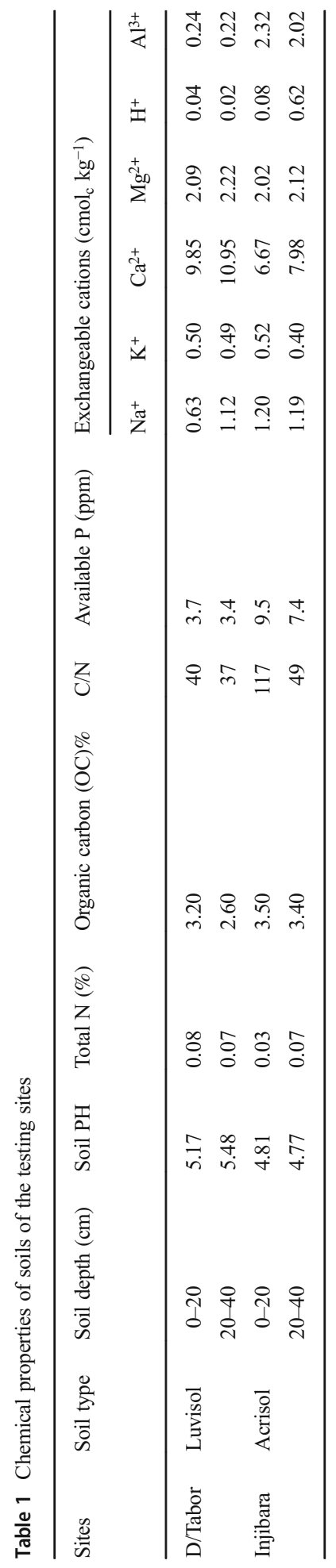


Canopy cover (CC) was assessed every 5 days starting from 30 days after planting using a $0.6 \mathrm{~m} \times 0.75 \mathrm{~m}$ frame with 100 grid squares, positioned each time over the same middle plants in a plot for each measurement. Squares filled with foliage for more than $50 \%$ were counted, and the percentage of filled grid squares was considered canopy cover percentage (CC\%). A total of 14 and 22 measurements were made from each plot at Injibara and Debre-Tabor, respectively. Based on the canopy cover measurements, a curve was fitted using beta thermal time for each assessment, and model parameters describing the curve were estimated using the NOLIN procedure of SAS, SAS Institute Inc., 2004 (Khan et al. 2013).

Days to maturity (DTM) was determined as the number of the days from emergence to the day at which more than $90 \%$ of the plants in a plot attained physiological maturity (90\% of the haulm tissues brown). The assessment was carried out every day starting from the time that early cultivars showed the first signs of maturity.

\section{Tuber Traits}

Harvesting was carried out once on October 10 and October 14, 2013 at Debre-Tabor and Injibara, respectively, when the last cultivars reached physiological maturity, and eight plants per plot were harvested and used to evaluate the following tuber traits. Tuber number per plant (TNPP) was recorded as the number of tubers collected from a matured plant at harvest. Average tuber weight (ATW) was the ratio of the weight of tubers per plant and number of tubers per plant at harvest. Tuber yield per plant (TYPP) was the average tuber yield per plant calculated taking the tuber yield (fresh weight) of all harvested plants from a net plot divided by number of plants harvested from that net plot.

Specific gravity (SG) was determined using the tuber-specific gravity procedure of weight in air and under water (Murphy and Goven 1959). In evaluating the SG of each cultivar, healthy and marketable-sized grade ( $20 \mathrm{~mm}$ and above) tubers were selected randomly from each cultivar at harvest. Then, tubers were cleaned and weighed both in air and water following the procedure of Murphy and Goven (1959). Specific gravity values were computed using the following formula:

$$
\mathrm{SG}=\frac{W_{1}}{W_{1}-W_{2}}
$$

where $\mathrm{SG}=$ specific gravity of the material, $\mathrm{W}_{1}=$ weight in air of the sample tuber in grams and $\mathrm{W}_{2}=$ weight of the sample completely immersed in water in grams. Tuber dry matter content (TDM\%) normally is determined as the ratio of dry tuber weight to fresh weight expressed in percentage. However, we determined TDM\% indirectly from SG using empirical conversion factors following the equation of Kleinkopf et al. (1987): TDM\%= $-214.9206+(218.1852 \times$ SG). Tuber dry weight $($ TDW) was estimated indirectly from specific gravity and tuber dry matter content in percent, using the following formula:

$$
\mathrm{TDW}=\frac{\mathrm{TDM} \% * \mathrm{TFW}}{100}
$$

where TDW = tuber dry weight in $\mathrm{g}, \mathrm{TDM} \%=$ tuber dry matter content, TFW $=$ fresh weight of the tuber in $\mathrm{g}$. 
Nitrogen use efficiency (NUE) is typically calculated as the yield per unit of $\mathrm{N}$ resource available to the plant (Moll et al. 1982). However, the method of NUE determination depends on the crop species and the objective of the study. In our case, NUE was determined as the tuber dry matter production, or dry weight of the tuber, per unit of $\mathrm{N}$ supplied.

\section{Data Processing}

The beta thermal time for canopy cover assessment was calculated from the date of emergence for each experimental unit, using the sigmoid part of the beta function for determinate growth (Yin et al. 2003), and a cardinal temperature (with $5.5^{\circ} \mathrm{C}$ as a base temperature, $23.37{ }^{\circ} \mathrm{C}$ as optimum and $34.58{ }^{\circ} \mathrm{C}$ as ceiling temperature) that determines the vegetative growth of potato (Khan 2012; Khan et al. 2013). Hourly temperature was collected from the Debre-Tabor weather station for Debre-Tabor and we used the local climate estimator (New_LocClim) in the FAO web site meteorological database for Injibara (FAO 2014).

The model for canopy development was fitted using the canopy cover data, beta thermal time for each assessment, and the NOLIN procedure of SAS (SAS, Institute Inc. 2004) (Yin et al. 2003). The canopy cover dynamics in potato as quantified by the grid method typically follows a pattern that can be divided into three major growing phases of the crop, i.e. the building phase, maximum cover phase and declining phase (Khan 2012; Khan et al. 2013). Estimated parameters with their standard errors were obtained after optimization. For each experimental unit we estimated the values of five model parameters (tm1, t1, t2, te and Vmax) according to Khan et al. (2013). The time (t) parameters were expressed in thermal time day ${ }^{-1}(\mathrm{td})$ : tml (the inflection point in the build-up phase of the growth curve), t1 (time point at which the canopy stabilized), t2 (onset of senescence), te (time of completely senesced canopy). The last parameter Vmax is the maximum canopy cover (the maximum vegetative growth stage of the crop) value with percentage of canopy cover as unit. Based on the canopy development curve model (Khan et al. 2013), the following additional parameters were calculated: $\mathrm{t} 2$-t 1 (duration of maximum canopy cover in td), te-t2 (duration of senescence), AP1 (area under the curve for canopy building phase in \% td), AP2 (area under the curve for maximum canopy cover phase in \% td), AP3 (area under the curve for the phase of senescence in \% td) and AUC (area under the curve for the entire crop growth cycle in \% td). The value of AUC represents the capacity of the crop to intercept solar radiation over the whole growing season (Vos 1995, 2009).

\section{Statistical Analysis}

To estimate the variance components for each trait, two types of analysis of variance (ANOVA) were performed using software Genstat 16th Edition. The first ANOVA was executed separately for each $\mathrm{N}$ level at each location following a randomized complete block design system using one-way ANOVA. The second ANOVA was performed for each location and across locations using the general linear model for split plot design with two $\mathrm{N}$ level treatments as main plot and the genotypes as sub-plot, two replications and two locations. Least significant difference (LSD) was used to separate the means at $1 \%$ and/or $5 \%$ level of significance. Clustering was carried out using SAS software version 9.3 based on the generalized $\mathrm{D}^{2}$ distances by average linkage method of 
hierarchical clustering called Unweighted Pair Group Methods with Arithmetic-average (UPGMA). Statistics, pseudo F statistic and pseudo t 2 statistic generated by SAS were examined to decide the number of optimum clusters.

Genetic distance within and between clusters was calculated using the generalized Mahalanobis's $\mathrm{D}^{2}$ statistics. The $\mathrm{D}^{2}$ is defined as $D^{2} i j=(x i-x j) S^{-1}(x i-x j)$

where $\mathrm{D}^{2} \mathrm{ij}$ is the distance between two clusters $\mathrm{i}$ and $\mathrm{j} ; X \mathbf{i}$ and $X \mathrm{j}$ are the two vector means of the traits for $\mathrm{i}^{\text {th }}$ and $\mathrm{j}^{\text {th }}$ groups, respectively, and $S^{-1}$ is the inverse of the pooled covariance (Mahalanobis 1936). The $\mathrm{D}^{2}$ value obtained for pairs of clusters was considered as the calculated value of Chi-squared $\left(\chi^{2}\right)$ and was tested for significance at the required level of probability against the tabulated values of $\chi^{2}$ for $p$ degrees of freedom, where $p$ is the number of characters considered (Singh and Chaudhary 1985).

Regression and correlation analysis were carried out between the traits measured in each specific environment for traits that had a significant $F$ test value. The variance components were computed using Genstat 16th Edition. The phenotypic (PCV) and genotypic (GCV) coefficients of variation were determined using the method defined by Burton and Devane (1953). The formula for GCV is the same as for PCV, with genotypic replacing phenotypic.

$$
P C V=\frac{\sqrt{\text { phenotypic variance }}}{\text { population mean for the trait }} \times 100
$$

Broad sense heritability was estimated from the total genetic variance using the method described by Falconer and Mackay (1996): $h^{2}=\sigma^{2} g /\left(\sigma^{2} g+\sigma^{2} e\right)$. The genetic advance (GA) expected under selection, assuming selection intensity of $5 \%$ was calculated by the formula suggested by Johnson et al. (1955): $G A=k \cdot h^{2} \sigma p$ where $k=$ selection intensity ( $k=2.06$ at $5 \%$ selection), $h^{2}=$ broad sense heritability and $\sigma p=$ phenotypic standard deviation. To study the inter-relationships among measured traits and their direct and indirect contributions to NUE under low and high $\mathrm{N}$ fertilizer level, means of traits that had high genetic variation were subjected to correlation and path analysis (Dewey and Lu 1959; Lal et al. 1997).

\section{Results}

\section{N Level Effects}

A summary of the trait values under low and high $\mathrm{N}$ regimes at each location is presented in Table 2. The responses to the $\mathrm{N}$ treatments were different from trait to trait. NUE, tuber dry matter percentage (TDM\%) and days to maturity (DTM) had higher mean values at Low N (LN) than at High $\mathrm{N}(\mathrm{HN})$ at both locations. The mean values of curve-derived canopy parameters, $\mathrm{tm} 1$ (the inflection point, during the canopy building growth phase), $\mathrm{t} 1$ (the time point when the crop reaches maximum canopy cover level), t2-t1 (the duration when the crop retains its maximum canopy), $\mathrm{t} 2$ (the time point when maximum canopy cover starts decline), te (the time point canopy cover zero) showed small differences between low and high $\mathrm{N}$ conditions.

Low $\mathrm{N}$ availability caused a significant $(P \leq 0.01)$ reduction $(23 \%$ in Debre-Tabor and $40 \%$ in Injibara) in potato maximum canopy cover (Vmax) (Table 2, Fig. 1). Similarly, the area under the canopy curve for the entire crop growth cycle (AUC), representing the total 
Table 2 Trait means of 97 potato cultivars evaluated at high N level (HN) and low N level (LN) in DebreTabor and Injibara

\begin{tabular}{|c|c|c|c|c|c|c|}
\hline \multirow[t]{3}{*}{ Traits } & \multicolumn{3}{|c|}{ Debre-Tabor } & \multicolumn{3}{|l|}{ Injibara } \\
\hline & \multicolumn{3}{|c|}{$\mathrm{N}$ levels } & \multicolumn{3}{|c|}{$\mathrm{N}$ levels } \\
\hline & $\mathrm{HN}$ & $\mathrm{LN}$ & $\begin{array}{l}\text { Difference in percent } \\
100(\mathrm{LN}-\mathrm{HN}) / \mathrm{HN}\end{array}$ & $\mathrm{HN}$ & LN & $\begin{array}{l}\text { Difference in percent } \\
100(\mathrm{LN}-\mathrm{HN}) / \mathrm{HN}\end{array}$ \\
\hline DTE & 13.5 & 13.1 & -4 & 13.9 & 13.0 & -7 \\
\hline $\mathrm{PH}$ & 44.2 & 36.0 & -19 & 27.3 & 15.7 & -42 \\
\hline SNPP & 3.8 & 3.7 & +4 & 3.8 & 3.6 & -4 \\
\hline Vmax & 69.5 & 53.3 & -23 & 62.0 & 37.1 & -40 \\
\hline $\operatorname{tm} 1$ & 7.9 & 8.1 & +2 & 9.6 & 10.6 & +10 \\
\hline $\mathrm{t} 1$ & 13.5 & 13.6 & +1 & 16.7 & 17.5 & +4 \\
\hline $\mathrm{t} 2$ & 17.7 & 16.6 & -5.7 & 21.5 & 24.0 & +11.3 \\
\hline $\mathrm{t} 2-\mathrm{t} 1$ & 4.2 & 3.0 & -27 & 4.8 & 6.5 & +35.4 \\
\hline te & 30.7 & 30.0 & -2 & 34.0 & 38.0 & +11.8 \\
\hline te-t2 & 13.0 & 13.4 & +3 & 12.5 & 14.3 & +14.6 \\
\hline AUC & 1314.0 & 948.0 & -28 & 1366.3 & 856.2 & -37 \\
\hline AP1 & 419.8 & 313.7 & -25 & 538.2 & 254.8 & -53 \\
\hline AP2 & 283.6 & 154.6 & -46 & 295.9 & 237.2 & -20 \\
\hline AP3 & 610.6 & 480.0 & -21 & 532.3 & 364.2 & -32 \\
\hline $\mathrm{LCC}$ & 40.4 & 37.9 & -6 & 47.3 & 42.0 & -11 \\
\hline $\mathrm{UCC}$ & 43.5 & 39.3 & -10 & 43.3 & 38.1 & -12 \\
\hline DTM & 69 & 68 & -1 & 76 & 80 & +4 \\
\hline TNPP & 8 & 7 & -16 & 8 & 5 & -38 \\
\hline TYPP & 460.5 & 322.0 & -30 & 424.2 & 219.8 & -48 \\
\hline ATW & 59.6 & 49.7 & -17 & 58.8 & 49.3 & -16 \\
\hline TDW & 46.0 & 36.9 & -19.8 & 47.6 & 32.7 & 31.3 \\
\hline TDM\% & 10.0 & 11.5 & +13 & 11.3 & 14.9 & +24 \\
\hline SG & 1.03 & 1.04 & +1 & 1.04 & 1.05 & +1 \\
\hline NUE & 0.38 & 0.92 & +142 & 0.39 & 0.82 & +110 \\
\hline
\end{tabular}

DTE days to emergence, $P H$ plant height $(\mathrm{cm}), S N P P$ stem number plant ${ }^{-1}$, Vmax maximum canopy cover in $\%, t m 1$ inflection point in thermal day (td), $t 1$ canopy stabilized in $t d, t 2$ onset of canopy senesced in td, $t 2-t 1$ duration for max canopy in td, te completely senesced canopy in td, $A U C$ total area under the canopy in \% td, $A P 1$ area for growth phase one in $\%$ td, $A P 2$ area for growth phase two in \% td, $A P 3$ area for growth phase three in \% td, $L C C$ lower leaf chlorophyll content (SPAD readings), UCC upper leaf chlorophyll content (SPAD readings), DTM days to maturity tuber, TNPP tuber number plant ${ }^{-1}, T Y P P$ tuber yield plant $^{-1}$ in $_{\mathrm{g}}$, $A T W$ average tuber weight in $\mathrm{g}, T D W$ tuber dry weight in $\mathrm{kg} \mathrm{ha}^{-1}, T D M \%$ tuber dry matter (\%), $S G$ specific gravity $\mathrm{g} \mathrm{g}^{-1}$ nitrogen use efficiency kg kg-1, HN high $\mathrm{N}\left(120 \mathrm{~kg} \mathrm{ha}^{-1}\right), L N$ low $\mathrm{N}\left(40 \mathrm{~kg} \mathrm{ha}^{-1}\right)$

light intercepted by a cultivar during the growth cycle, was significantly $(P \leq 0.01)$ affected by low $\mathrm{N}$ availability. Among the three growing phases, the effect of $\mathrm{N}$ on area under the curve in the building phase (AP1) and area in the senescence phase (AP3) was considerable compared to area under the curve in phase two (AP2) in Injibara, while in Debre-Tabor, the effect was bigger in AP2 (Table 2). The extent of the $\mathrm{N}$ effect was 


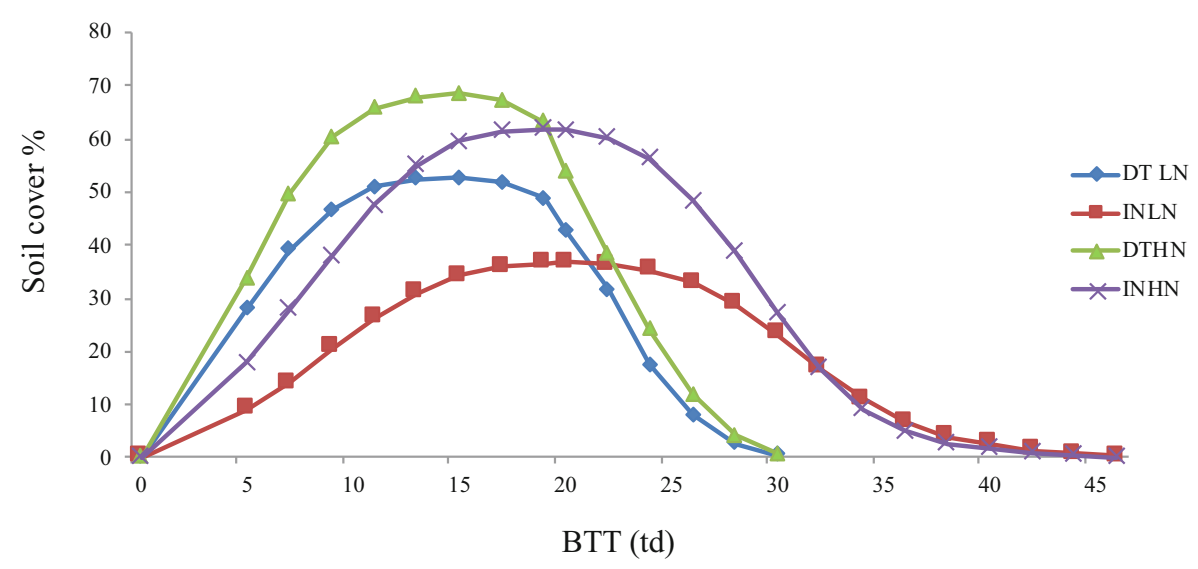

Fig. 1 Measurements of canopy development curve at low and high N regime in Injibara and Debre-Tabor. INHN = Injibara high N, INLN = Injibara low N, DTLN = Debre-Tabor low N, DTHN = Debre-Tabor high N and $\mathrm{BTT}=$ beta thermal time in ${ }^{\circ} \mathrm{C}$ day

different between the two locations. AUC was reduced by $28 \%$ at Debre-Tabor and $37 \%$ at Injibara. Area under the curve in the building phase 1 (AP1) was reduced by $25 \%$ at Debre-Tabor and 53\% at Injibara, while area in phase 2 (AP2) and 3 (AP3), respectively, was reduced by 46 and $21 \%$ in Debre-Tabor and 20 and $32 \%$ in Injibara. The difference in response to $\mathrm{N}$ of these parameters at least partly resides in the opposite response of the maximum canopy duration (t2-t1) in Injibara compared to Debre-Tabor (increased in Injibara at low $\mathrm{N}$, while decreased in Debre-Tabor (Table 2)).

The effect of $\mathrm{N}$ levels on tuber traits of the cultivars was substantial (Table 2). Average tuber weight (ATW) was significantly reduced under low $\mathrm{N}$ compared to high $\mathrm{N}$, and so were tuber number per plant (TNPP), and total tuber yield per plant (TYPP), at both locations. TYPP was reduced by $30 \%$ in Debre-Tabor and $48 \%$ in Injibara. Of the two tuber yield components, TNPP was reduced by $16 \%$ in Debre-Tabor and $38 \%$ in Injibara, while ATW was reduced by $17 \%$ in Debre-tabor and $16 \%$ in Injibara. This higher tuber yield reduction at Injibara thus was mainly caused by reduction in tuber number, and may be related to the low $\mathrm{pH}$ (acidic property) of the soil. In Injibara, the soil acidity and rainfall are high compared to Debre-Tabor, which indicates that the nitrogen applied in Injibara may be vulnerable for loss due to leaching and denitrification as compared to less acidic soil and low rainfall areas. NUE increased by $142 \%$ in Debre-Tabor and $110 \%$ in Injibara at low N compared to high $\mathrm{N}$ levels. TDM\% was higher in Injibara under both $\mathrm{N}$ conditions and increased under low $\mathrm{N}$ conditions.

\section{Location and Cultivar Effects}

The variation among cultivars was significant for all traits at both locations (Table 3). The effect of location was significant for most measured traits except for ATW, the time to complete senesced canopy te, NUE and AUC (Table 3). The non-significant variation between the two locations for AUC is due to the counterbalancing effect of higher maximum canopy cover (Vmax) but lower cumulative thermal time for the growth period in Debre Tabor compared to Injibara (Fig. 1). Cultivars in the Injibara trial matured later and were harvested later as well. The duration for maximum canopy 
cover phase ( $\mathrm{t} 2$ - $\mathrm{t} 1)$ was relatively short in both Debre-Tabor and Injibara. Based on the maturity data collected in this experiment, we have classified our cultivars into early, intermediate and late maturity groups. Differences between the late maturity group and the intermediate and early maturity group were visible for most traits (including TYPP, TDM\% and AUC) under low and high N conditions in Debre-Tabor. The late maturity group cultivars had higher values of AUC as well as TYPP at both N levels in DebreTabor (Fig. 2). In Injibara however, the variation between the maturity groups was lower, and even negligible for TYPP at both $\mathrm{N}$ levels, even though the late maturity group had higher values for AUC compared to the early and intermediate maturity group (Fig. 2).

Dutch cultivars on average performed differently to the Ethiopian cultivars. However, most Dutch cultivars were classified in the early and intermediate maturity group while most Ethiopian cultivars clustered in the late maturity group at both locations, suggesting that maturity was the main factor underlying the variation between the Ethiopian and the Dutch cultivars. To test this, Ethiopian and Dutch cultivars clustered in the same maturity group were compared, and this revealed that in the late maturity cluster, the Ethiopian cultivars in Injibara performed indeed better than the Dutch cultivars for AUC especially under high $\mathrm{N}$ conditions, but had lower tuber yield under both $\mathrm{N}$ conditions (Fig. 3), indicating that the Ethiopian cultivars in Injibara were not able to translate higher AUC, which reflects a higher light interception capacity, to higher yields at this location.

The interaction effect of $\mathrm{N}$ level $\times$ genotype was significant for DTE and ATW, and highly significant for PH, Vmax, AP1, te, LCC, DTM, TNPP and TYPP. N level $\times$ location interaction was significant for PH, Vmax, AUC, AP1, AP2, tm1, t2, t2-t1, te LCC, DTM, TNPP and TYPP, TDM and NUE. Location $\times$ genotype was significant for DTE and Vmax and highly significant for PH, AP1, te, LCC, DTM, TNPP, ATW, TYPP and NUE. The three-way interaction $(\mathrm{N}$ level $\times$ location $\times$ genotype $)$ was not significant for almost all characters except LCC and tuber dry weight (TDW) (Table 3).

\section{Cluster Analysis}

Cluster analysis was performed based on the genotype means of 12 quantitative traits (Supplementary Tables 4 and 5), in order to visualize genetic relationships of cultivar phenotypes at low and high $\mathrm{N}$ conditions across locations. Linked traits with double contribution (collinearity effect) were excluded from the cluster analysis. Means over the two locations were used as input for Unweighted Pair Group Method with Arithmetic Mean (UPGMA) hierarchical clustering and the 97 cultivars were clustered into 9 and 11 genetically distinct classes at low and high $\mathrm{N}$ at an average distance cut off value of 1.0 and 0.8 , respectively. However, some clusters had a different composition under low vs high $\mathrm{N}$ levels. The group size varied from 1 to 84 cultivars at low $\mathrm{N}$ and from 1 to 63 cultivars at high $\mathrm{N}$ (Figs. 4 and 5).

Clusters I, II, III, IV and V consisted of more than one cultivar, while Zengena, V9, V13 and Dagim were cultivars that existed as singletons at low N. At high N, cluster I to cluster VII were clusters that contained more than one cultivar whereas Berber, V9, Fabula and Agerie were cultivars that existed as singletons. Most of the cultivars grouped in a single cluster (cluster I) at both $\mathrm{N}$ levels; $87 \%$ at low $\mathrm{N}$ and $65 \%$ at high N. The Ethiopian cultivars Ater-Ababa, Awash and Gudenie were included in the largest 
Table 3 Analysis of variance of 22 traits of 97 potato cultivars in Debre-Tabor and Injibara at different N levels

\begin{tabular}{|c|c|c|c|c|c|c|c|}
\hline \multirow{3}{*}{$\begin{array}{l}\text { Traits } \\
\text { DF }\end{array}$} & \multicolumn{7}{|c|}{ Significance of $F$ value } \\
\hline & Genotype (G) & Location (L) & $\mathrm{N}$ level $(\mathrm{N})$ & $\mathrm{G} \times \mathrm{L}$ & $\mathrm{G} \times \mathrm{N}$ & $\mathrm{N} \times \mathrm{L}$ & $\mathrm{G} \times \mathrm{N} \times \mathrm{L}$ \\
\hline & 96 & 1 & 1 & 96 & 96 & 1 & 96 \\
\hline DTE & $* *$ & $* *$ & $* *$ & $*$ & $*$ & ns & ns \\
\hline $\mathrm{PH}$ & $* *$ & $*$ & $* *$ & $* *$ & $* *$ & $* *$ & ns \\
\hline SNPP & $* *$ & $* *$ & ns & $\mathrm{ns}$ & $\mathrm{ns}$ & $\mathrm{ns}$ & ns \\
\hline Vmax & $* *$ & $* *$ & $* *$ & $*$ & $* *$ & $* *$ & ns \\
\hline AUC & $* * *$ & ns & $* *$ & $\mathrm{~ns}$ & $* * *$ & $* * *$ & ns \\
\hline AP1 & $* * *$ & $* * *$ & $* * *$ & $* *$ & $\mathrm{~ns}$ & $* * *$ & $\mathrm{~ns}$ \\
\hline Ap2 & $* * *$ & $* * *$ & $* *$ & $\mathrm{~ns}$ & $\mathrm{~ns}$ & $* * *$ & $\mathrm{~ns}$ \\
\hline AP3 & $* * *$ & $* * *$ & $* *$ & $\mathrm{~ns}$ & ns & ns & $\mathrm{ns}$ \\
\hline $\operatorname{tm} 1$ & $* * *$ & $* * *$ & $\mathrm{~ns}$ & $\mathrm{~ns}$ & $\mathrm{~ns}$ & $* * *$ & ns \\
\hline $\mathrm{t} 1$ & $* *$ & $* *$ & ns & $\mathrm{ns}$ & $\mathrm{ns}$ & ns & $\mathrm{ns}$ \\
\hline $\mathrm{t} 2$ & $* *$ & $* * *$ & ns & $\mathrm{ns}$ & ns & $* * *$ & $\mathrm{~ns}$ \\
\hline t2-t1 & ns & $* * *$ & ns & ns & ns & $* * *$ & ns \\
\hline te-t2 & $* * *$ & $\mathrm{~ns}$ & ns & $\mathrm{ns}$ & ns & $\mathrm{ns}$ & ns \\
\hline te & $* * *$ & $* * *$ & $\mathrm{~ns}$ & $* * *$ & $\mathrm{~ns}$ & $* * *$ & ns \\
\hline LCC & $* *$ & $* *$ & $* *$ & $* *$ & $* *$ & $* *$ & $* *$ \\
\hline DTM & $* *$ & $* *$ & $\mathrm{~ns}$ & $* *$ & $* *$ & $* *$ & $\mathrm{~ns}$ \\
\hline TNPP & $* *$ & $* *$ & $* *$ & $* *$ & $* *$ & $* *$ & ns \\
\hline TYPP & $* *$ & $* *$ & $* *$ & $* *$ & $* *$ & $* *$ & ns \\
\hline ATW & $* *$ & $\mathrm{~ns}$ & $* *$ & $* *$ & $*$ & ns & $\mathrm{ns}$ \\
\hline TDW & $* *$ & $* *$ & $* *$ & $* *$ & $\mathrm{~ns}$ & $* *$ & $* *$ \\
\hline TDM\% & $* *$ & $* *$ & $* *$ & $\mathrm{~ns}$ & ns & $* *$ & ns \\
\hline $\mathrm{SG}$ & $* *$ & $* *$ & ns & ns & ns & $* *$ & ns \\
\hline NUE & $* *$ & $\mathrm{~ns}$ & $* *$ & $* *$ & $\mathrm{~ns}$ & $*$ & $\mathrm{~ns}$ \\
\hline
\end{tabular}

$D F$ degrees of freedom, $n s$ not significant, $D T E$ days to emergence, $P H$ plant height $(\mathrm{cm}), S N P P$ stem number plant $^{-1}$, Vmax maximum canopy cover in $\%, t m 1$ inflection point in thermal day (td), $t 1$ canopy stabilized in td, $t 2$ onset of canopy senesced in td, $t 2-t 1$ duration for max canopy in td, te completely senesced canopy in td, $A U C$ total area under the canopy in \% td, $A P 1$ area for growth phase one in \% td, $A P 2$ area for growth phase two in $\% \mathrm{td}, A P 3$ area for growth phase three in \% td, LCC lower leaf chlorophyll content, DTM days to maturity, Tuber TNPP tuber number plant ${ }^{-1}, T Y P P$ tuber yield plant $^{-1}$ in $\mathrm{g}, A T W$ average tuber weight in $\mathrm{g}$, $T D W$ tuber dry weight in $\mathrm{kg} \mathrm{ha}^{-1}, T D M \%$ tuber dry matter (\%), SG specific gravity $\mathrm{g} \mathrm{g}^{-1}$ nitrogen use efficiency $\mathrm{kg} \mathrm{kg}^{-1}$

*Significant at $P \leq 0.05$; **significant at $P \leq 0.01$; ***significant at $P \leq 0.001$

cluster (cluster I) at low N level, the rest were Dutch cultivars. Most Dutch cultivars clustered in the main cluster I, while the Ethiopian cultivars distinctly grouped in clusters IV and V at low $\mathrm{N}$ and in clusters IV, VI and VII at high $\mathrm{N}$ level, suggesting the presence of significant genetic distance between the Dutch and the Ethiopian potato cultivars. 


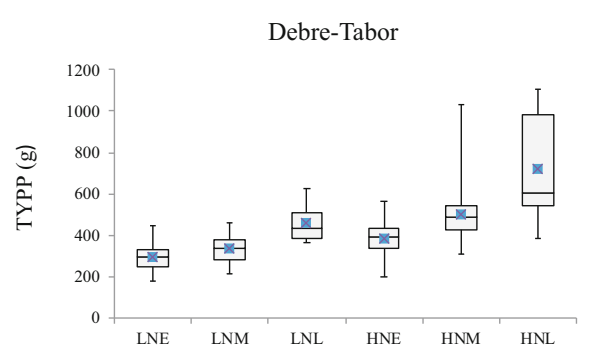

Injibara
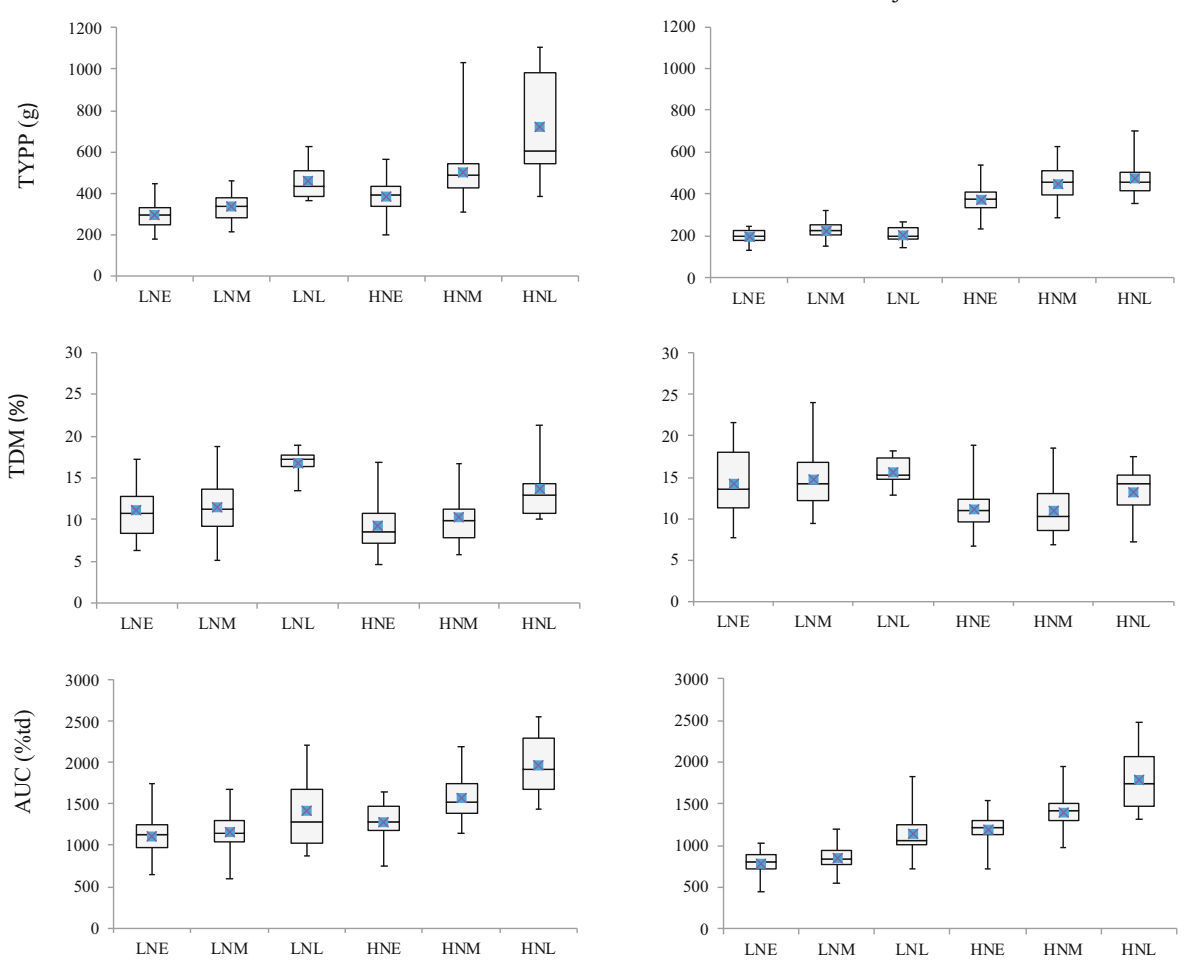

Fig. 2 Box plots of selected traits to show the mean performance of cultivars in their maturity group combined with nitrogen levels in Debre-Tabor and Injibara. The grouping elements on the $\mathrm{x}$-axis are a combination of $\mathrm{N}$ levels and maturity groups. $\mathrm{LNE}=$ low nitrogen with early cultivars, $\mathrm{LNM}=$ low nitrogen with intermediate cultivars, $\mathrm{LNL}=$ low nitrogen with late cultivars, $\mathrm{HNE}=$ high nitrogen with early cultivars, $\mathrm{HNM}=$ high nitrogen with intermediate cultivars, $\mathrm{HNL}=$ high nitrogen with late cultivars

Significant $(P \leq 0.01) \mathrm{D}^{2}$ was observed between most clusters (supplementary Tables 2 and 3). With the exception of genetic distance between cluster I and II at low $\mathrm{N}$ and between cluster I and clusters III and $\mathrm{V}$ at high $\mathrm{N}$, the average inter-cluster squared distances $\left(\mathrm{D}^{2}\right)$ between clusters were significant $(P \leq 0.05$ and $P \leq 0.01)$ at both $\mathrm{N}$ levels. There was a significant $(P \leq 0.01) \mathrm{D}^{2}$ difference between the largest cluster (cluster I) and clusters III, IV and V at low N. The $\mathrm{D}^{2}$ between cluster I and clusters IV, VI and VII was highly significant $(P \leq 0.01)$ at high $\mathrm{N}$. The lowest inter-cluster distance was recorded between clusters I and II with a genetic distance value of 16.52 at low $\mathrm{N}$ and between clusters I and III with a genetic distance value 12.34 at high $\mathrm{N}$, indicating the relatively high relatedness of the cultivars included in the two large clusters at both $\mathrm{N}$ levels. The highest inter-cluster genetic distance was observed between two singleton cultivars, Zengena and V13, with a genetic distance of 296.14 at low N, and between cluster V and a single cultivar, Agerie, with a genetic distance of 520.06 at high N. The traits DTM, PH, AUC, TYPP and NUE contributed most to the difference between the Dutch and the Ethiopian set of cultivars at both $\mathrm{N}$ levels (supplementary Tables 4 and 5). Trait means of NUE and AUC under low N, and DTM and TNPP under high N conditions, were the main cause for the significant genetic distance difference between 
Injibara
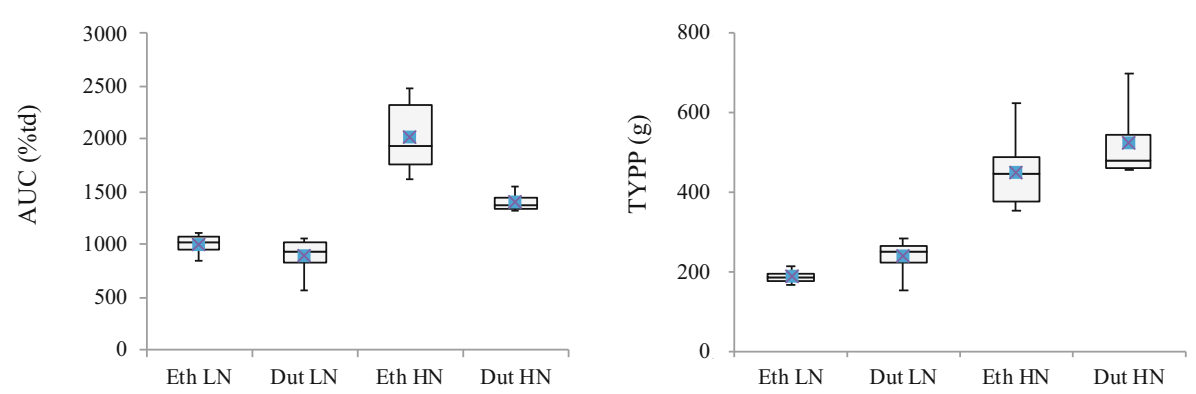

Fig. 3 Box plots of tuber yield per plant and area under the canopy curve (AUC) to show the mean performance of the Ethiopian and Dutch cultivars in the late maturity group in Injibara. The grouping elements on the $\mathrm{x}$-axis are a combination of origin of cultivars and $\mathrm{N}$ levels. Eth $\mathrm{LN}=$ Ethiopian cultivars at low $\mathrm{N}$, Dut $\mathrm{LN}=$ Dutch cultivars at low $\mathrm{N}$, Eth $\mathrm{HN}=$ Ethiopian cultivars at high $\mathrm{N}$, Dut $\mathrm{HN}=$ Dutch cultivars at high $\mathrm{N}$

Zengena and V13, and between cluster V and Agerie. Agerie, the Ethiopian traditional cultivar, was distinct mainly for its high number of tubers and late maturity.

\section{Estimates of Genetic Parameters}

Studies on genetic parameters and trait associations of potato provide information about the expected response of different traits to selection and help in developing optimal breeding strategies (Gopal 1999). We classified the observed variation in the potato cultivars into heritable and non-heritable components, and values for broad sense heritability $\left(h^{2}\right)$, coefficient of phenotypic variation (PCV) and genotypic variation (GCV), and genetic advance as percentage of mean (GA\%) obtained under low and high $\mathrm{N}$ level are presented in supplementary Tables 6 and 7. With the exception of $V_{\max }$ and TDM\% at low $\mathrm{N}$, and NUE at both $\mathrm{N}$ levels in Injibara, estimates of $h^{2}$ were high for the traits at both $\mathrm{N}$ levels and in both locations. Similarly, all traits had high GA\% except for UCC and DTM. $h^{2}$ varied over treatments and locations between 0.33 and 0.95 . NUE has high $h^{2}$ values in Debre-Tabor at low and high $\mathrm{N}$ levels ( 0.80 and 0.72 , respectively), but was only 0.4 at both $\mathrm{N}$ levels in Injibara, indicating that the contribution of the environment to the total NUE variation was high in Injibara compared to Debre-Tabor.

The differences of $h^{2}$ values of traits under high and low $\mathrm{N}$ condition were small in most of the traits at both locations. With the exception of ATW, TNPP and UCC in Injibara, and TYPP and NUE in Debre-Tabor, all traits had higher $h^{2}$ values at high $\mathrm{N}$ than at low $\mathrm{N}$ conditions indicating that the environmental factors affect the measured traits more under $\mathrm{N}$-limited conditions compared to under high $\mathrm{N}$ conditions. The differences between PCV and GCV were minimal for all measured traits over treatments and locations, revealing that the contribution of the genetic factors to the total phenotypic variation was large compared to the environmental factors, in line with the relatively high heritability estimates. For most traits considered in this study, a high value of genetic parameter estimates was observed at low and high $\mathrm{N}$ levels and across locations, suggesting that the measured traits in our experimental setup can be used for genetic improvement through selection. 


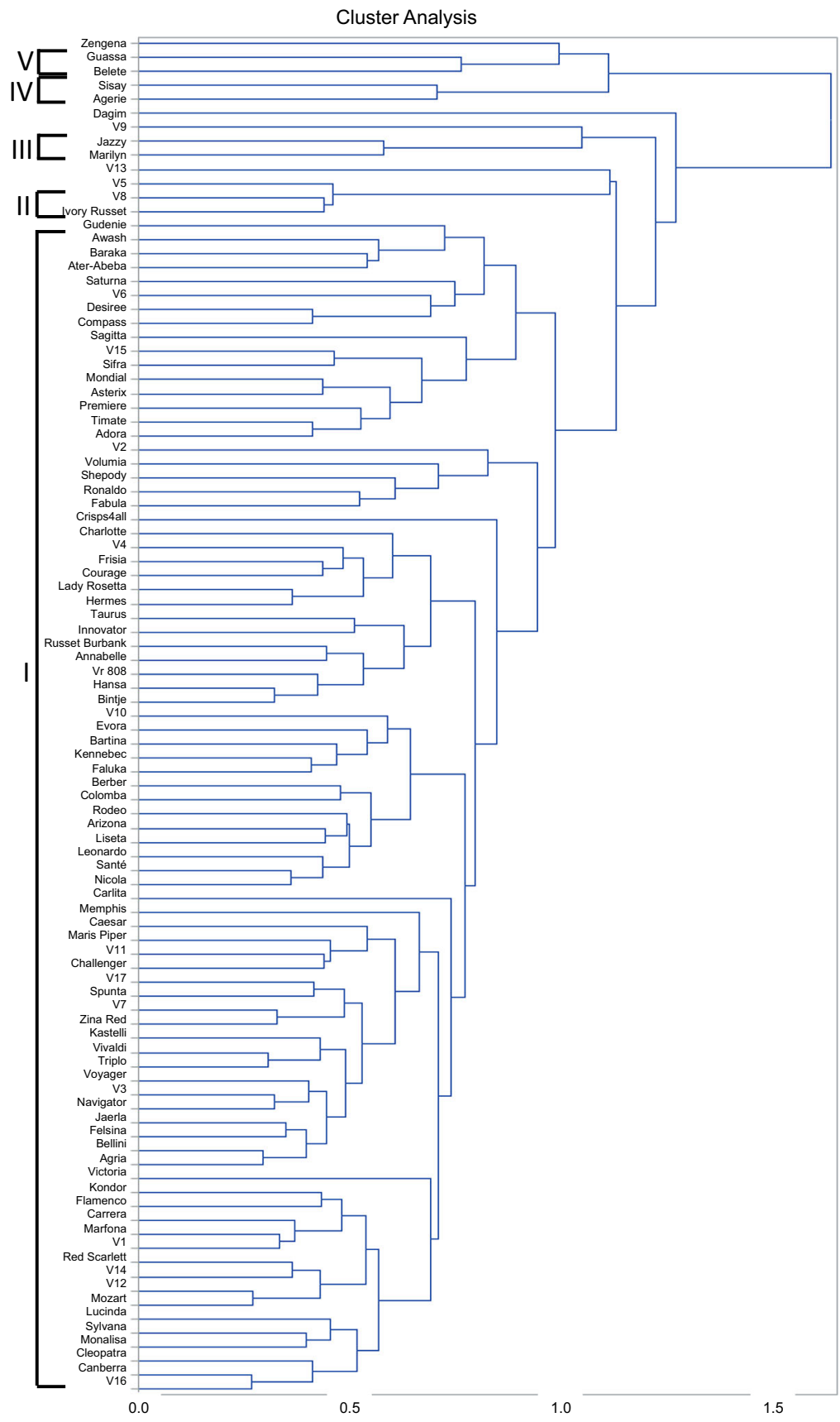

Average Distance Between Clusters

Fig. 4 UPGMA (based on average genetic distance and with cut-off-point 1.0) of 97 potato cultivar similarities based on 12 agronomic and physiological NUE-related quantitative traits at low N 


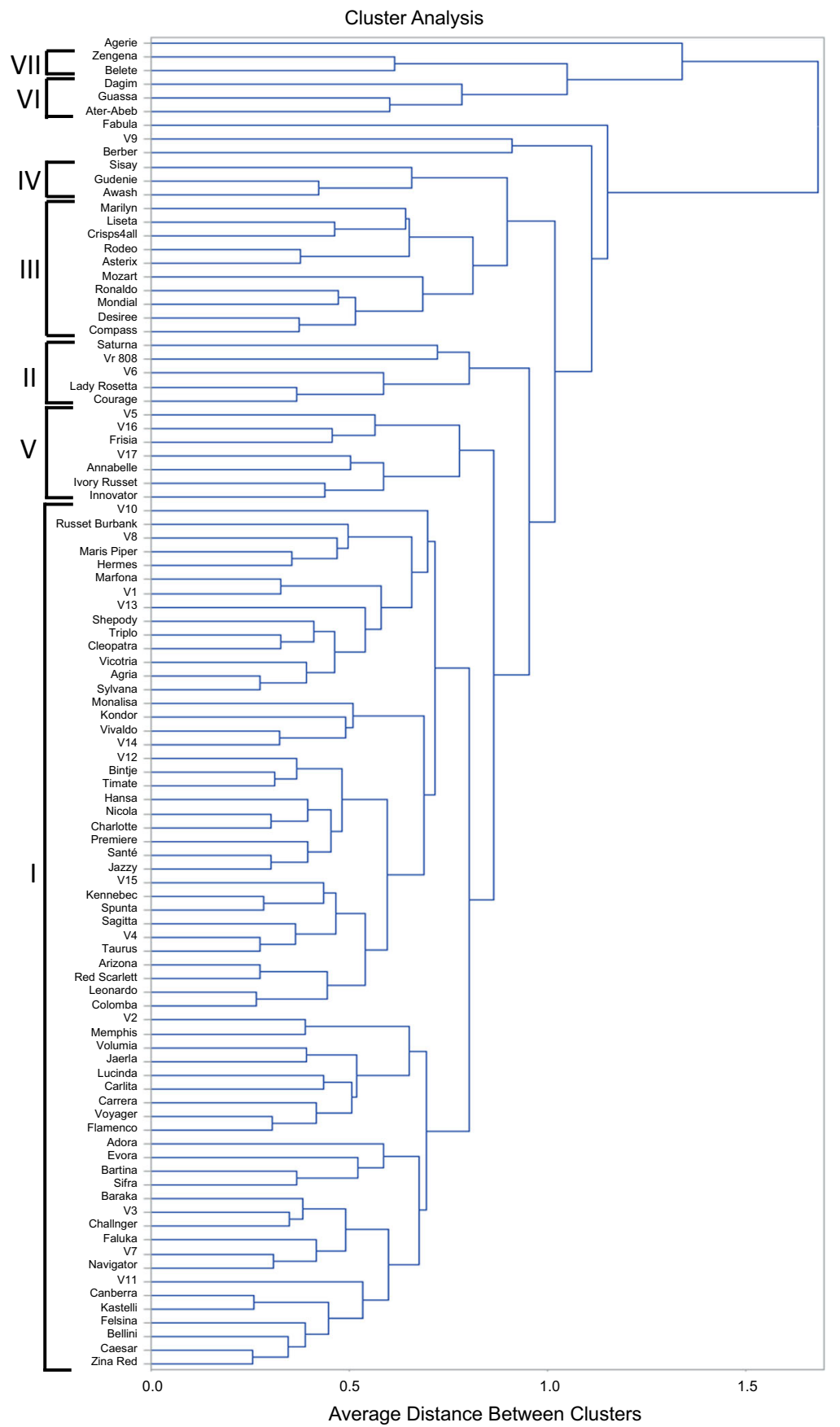

Fig. 5 UPGMA (based on average genetic distance and, with cut-off-point 0.8) of 97 potato cultivar similarities based on 12 agronomic and physiological NUE-related quantitative traits at high $\mathrm{N}$ 


\section{Correlation and Path Analysis}

Information of mutual association between yield and yield component traits is important for effective utilization of genetic resources. Estimations of locationcombined phenotypic correlation coefficients between traits for the 97 cultivars under low $\mathrm{N}$ and high $\mathrm{N}$ are presented in Table 4. Significant phenotypic correlation coefficients were observed between NUE and all traits except ATW and UCC across N levels. Most of the traits showed higher phenotypic correlation coefficient values at high $\mathrm{N}$ level than at low $\mathrm{N}$ level. The correlation coefficients of traits between low and high $\mathrm{N}$ level was significant except UCC and te (Table 4), which implies the effect of N levels was small on the association of traits.

The correlations between traits presented in Table 4 do not indicate the cause-and-effect relationship, because different traits may contribute positively or negatively to the observed correlation coefficient between the two traits due to the physiological interrelationships among traits. Estimation of correlation components using path analysis revealed that the largest direct contributions to the variation observed in NUE under low and high $\mathrm{N}$ conditions were of TDM\% and TNPP (Figs. 6 and 7). ATW also had a strong positive direct effect on NUE, even though the phenotypic correlation coefficient between the two traits was not significant. This weak correlation between ATW and NUE resulted from the strong negative indirect effect of ATW via TNPP and TDM\% on NUE. Except in Debre-Tabor at high $\mathrm{N}$ level, TDM\% had the strongest direct influence on NUE at both $\mathrm{N}$ levels and in both locations. Some traits did not have a strong direct effect on NUE, but they had a strong indirect effect via the other traits (Figs. 6 and 7). For instance, AUC had a negligible direct effect on NUE, while its high indirect effect via TDM\% and TNPP counterbalances the negligible direct effect on the observed variation of NUE. ATW and TNPP had a strong direct contribution to the variation observed on NUE, but their indirect effect via each other on NUE was negative.

Table 4 Pearson phenotypic correlation coefficients under low N (below bold diagonal) and high N (above bold diagonal) among 13 agronomic and physiological NUE related traits for 97 cultivars across locations. The diagonal gives correlation coefficients of the same trait between high $\mathrm{N}$ and low $\mathrm{N}$

\begin{tabular}{|c|c|c|c|c|c|c|c|c|c|c|c|c|c|}
\hline Low $\mathrm{N}$ & $\begin{array}{c}\text { High N } \\
\text { PH }\end{array}$ & UCC & $\mathrm{t} 1$ & $\mathrm{t} 2$ & te & $V \max$ & AUC & DTM & TNPP & ATW & TYPP & TDM $\%$ & NUE \\
\hline $\mathrm{PH}$ & $0.95^{* * *}$ & -0.02 & $0.29 * *$ & $0.42^{* * *}$ & $0.61^{* * *}$ & $0.76^{* * *}$ & $0.78^{* * *}$ & $0.69 * * *$ & $0.37^{* * *}$ & $0.21^{*}$ & $0.65 * * *$ & $0.27^{* *}$ & $0.69^{* * *}$ \\
\hline UCC & -0.10 & 0.19 & -0.11 & 0.07 & 0.00 & -0.17 & -0.13 & 0.01 & -0.16 & $0.20^{*}$ & -0.01 & -0.01 & -0.02 \\
\hline $\mathrm{t} 1$ & $0.43^{* * *}$ & -0.11 & $0.55^{* * *}$ & $0.46^{* * *}$ & $0.48^{* * *}$ & $0.32^{* *}$ & $0.35^{* *}$ & $0.34^{* *}$ & $0.22^{*}$ & 0.02 & $0.31^{* *}$ & 0.04 & $0.28^{* *}$ \\
\hline $\mathrm{t} 2$ & $0.33^{* *}$ & -0.12 & $0.42^{* * *}$ & $0.46^{* * *}$ & $0.42^{* * *}$ & $0.37 * * *$ & $0.52 * * *$ & $0.39 * * *$ & 0.17 & 0.04 & $0.44^{* * *}$ & $0.21^{*}$ & $0.48^{* * *}$ \\
\hline te & $0.58^{* * *}$ & -0.09 & $0.60^{* * *}$ & $0.41^{* * *}$ & $0.24^{*}$ & $0.65^{* * *}$ & $0.79 * * *$ & $0.84^{* * *}$ & $0.29 * *$ & $0.31 * *$ & $0.64 * * *$ & $0.25^{*}$ & $0.68^{* * *}$ \\
\hline$V \max$ & $0.44^{* * *}$ & $-0.25^{*}$ & $0.49 * * *$ & $0.35^{* *}$ & $0.50^{* * *}$ & 0.62 *** & $0.95^{* * *}$ & $0.66^{* * *}$ & $0.59 * * *$ & 0.09 & $0.73 * * *$ & $0.25^{*}$ & $0.76^{* * *}$ \\
\hline AUC & $0.52 * * *$ & $-0.20 *$ & $0.56 * * *$ & $0.51^{* * *}$ & $0.66 * * *$ & $0.95 * * *$ & $0.71^{* * *}$ & $0.75 * * *$ & $0.55^{* * *}$ & 0.13 & $0.78^{* * *}$ & $0.30 * *$ & $0.83^{* * *}$ \\
\hline DTM & $0.64^{* * *}$ & -0.09 & $0.42^{* * *}$ & $0.27 * *$ & $0.76^{* * *}$ & $0.35^{* *}$ & $0.46^{* * *}$ & $0.63^{* * *}$ & $0.32 * *$ & $0.32 * *$ & $0.71^{* * *}$ & $0.29 * *$ & $0.75^{* * *}$ \\
\hline TNPP & $0.37 * * *$ & $-0.24 *$ & $0.28 * *$ & $0.35 * *$ & $0.39 * * *$ & $0.40^{* * *}$ & $0.47^{* * *}$ & $0.36^{* * *}$ & $0.81^{* * *}$ & $-0.58 * * *$ & $0.41^{* * *}$ & $0.40^{* * *}$ & $0.58 * * *$ \\
\hline ATW & $0.21^{*}$ & $0.23^{*}$ & 0.09 & -0.08 & 0.10 & -0.11 & -0.09 & 0.05 & $-0.58 * * *$ & $0.79^{* * *}$ & $0.40^{* * *}$ & $-0.49 * * *$ & 0.08 \\
\hline TYPP & $0.65^{* * *}$ & -0.03 & $0.53^{* * *}$ & $0.40^{* * *}$ & $0.59^{* * *}$ & $0.41^{* * *}$ & $0.51^{* * *}$ & $0.47^{* * *}$ & $0.41^{* * *}$ & $0.40^{* * *}$ & $0.62^{* * *}$ & -0.10 & $0.80^{* * *}$ \\
\hline TDM $\%$ & $0.23 *$ & -0.10 & 0.07 & 0.04 & $0.25 *$ & $0.32^{* *}$ & $0.33^{* *}$ & $0.23^{*}$ & $0.35^{* *}$ & $-0.39 * * *$ & -0.03 & $0.76^{* * *}$ & $0.44^{* * *}$ \\
\hline NUE & $0.42 * * *$ & -0.06 & $0.50^{* * *}$ & $0.33 * *$ & $0.52^{* * *}$ & $0.58^{* * *}$ & $0.60^{* * *}$ & $0.47 * * *$ & $0.28^{* *}$ & 0.09 & $0.44 * * *$ & $0.39 * * *$ & $0.78^{* * *}$ \\
\hline
\end{tabular}

Significance level, $* P \leq 0.05, * * P \leq 0.01, * * * P \leq 0.001$ 


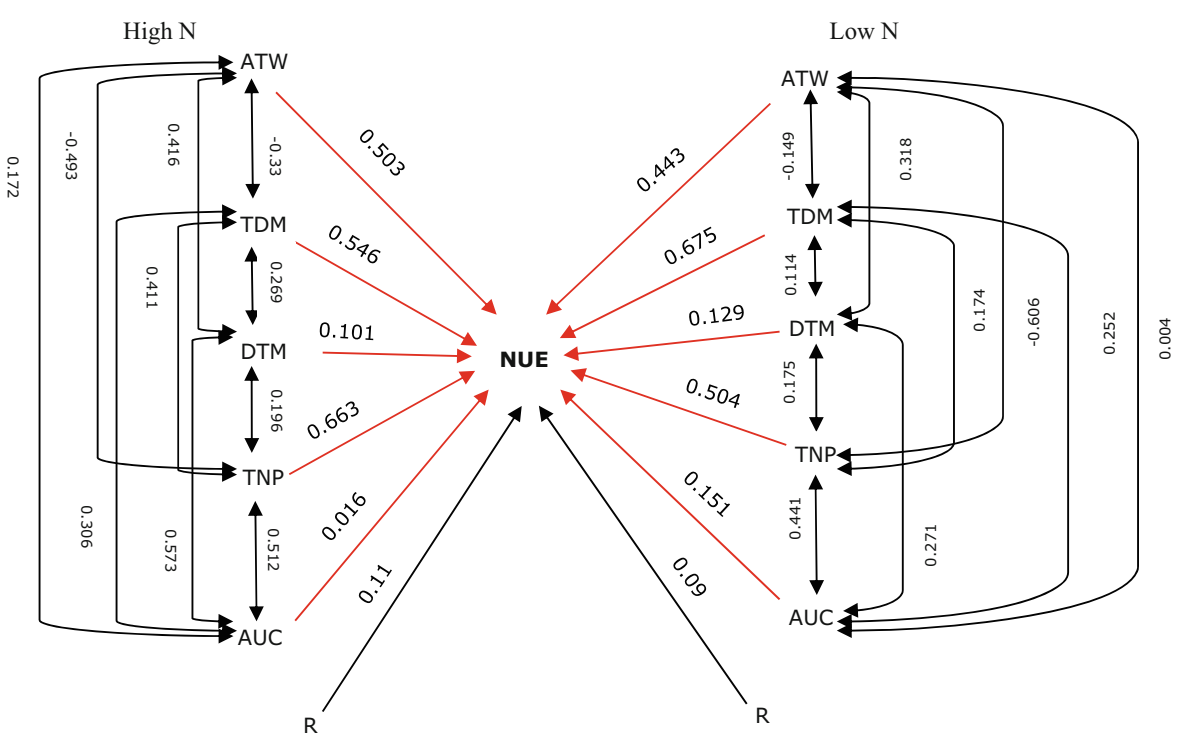

Fig. 6 Diagram showing correlations and path coefficients of 5 factors influencing NUE under high and low $\mathrm{N}$ condition in Debre-Tabor. Double arrowhead lines indicate mutual association as measured by correlation coefficients and the red colour single arrowed lines denote direct influence as measured by path coefficients. Negligible correlation and path coefficients were omitted. NUE: nitrogen use efficiency, ATW: average tuber weight, TDM: tuber dry matter in \%, DTM: days to maturity, TNPP: tuber number per plant, AUC: area under the canopy curve, R: residual effect

High N

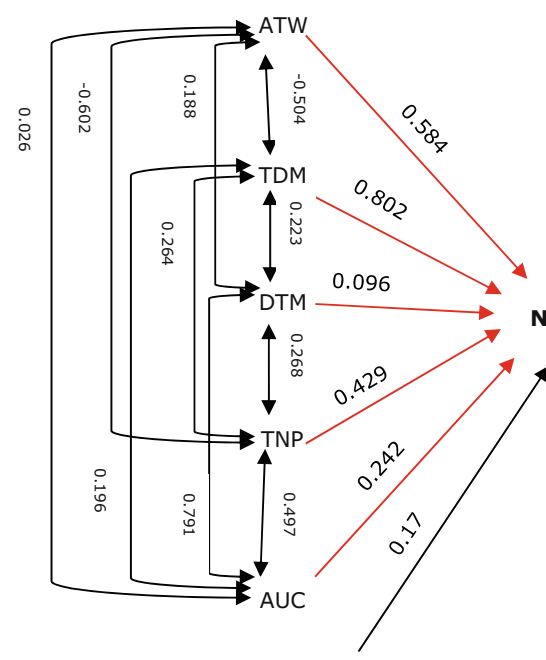

$\mathrm{R}$
Low N

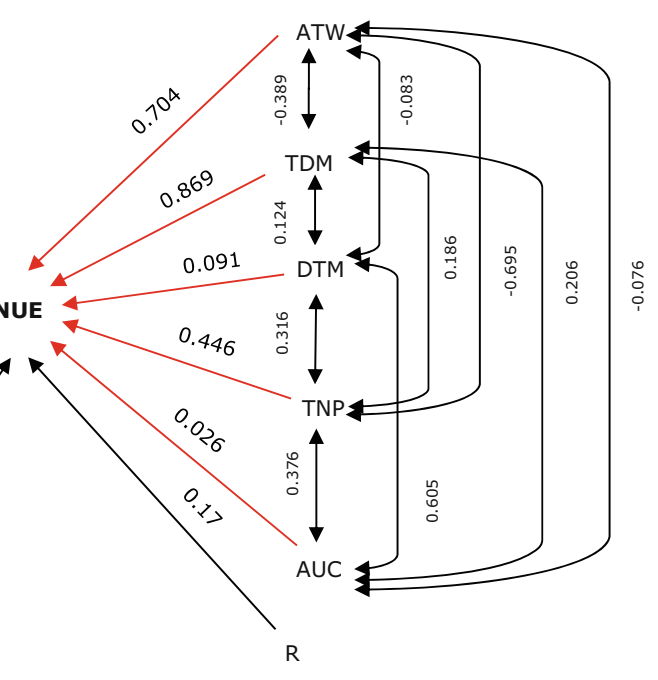

Fig. 7 Diagram showing correlations and path coefficients of 5 factors influencing NUE under high and low $\mathrm{N}$ condition in Injibara. Double arrowhead lines indicate mutual association as measured by correlation coefficients and the red colour single arrowed lines denote direct influence as measured by path coefficients. Negligible correlation and path coefficients are omitted. NUE: nitrogen use efficiency, ATW: average tuber weight, TDM: tuber dry matter in \%, DTM: days to maturity, TNP: tuber number per plant, AUC: area under the canopy curve, R: residual effect 


\section{Discussion}

Genetic variation is a precondition for breeding programmes aimed at potato improvement. The results of analysis of variance of the present study showed that the effect of genotype was significant for almost all of the measured traits including NUE, which implies the tested cultivar set had significant variation that may be used for breeding to improve NUE in potato. For several traits, the Ethiopian cultivars behaved distinctly different from the Dutch cultivars. Dutch cultivars showed rapid initial canopy development and they matured early compared to the Ethiopian cultivars at both $\mathrm{N}$ levels and locations. This may be associated with limited adaptation to the experimental conditions, since the Ethiopian cultivars were selected under Ethiopian conditions while the Dutch cultivars were selected for Western-European, long day conditions. Haverkort (1990) suggested that potato cultivars adapted to long day conditions may mature earlier and senesce between 60 and 70 days after emergence when grown around the equator. This physiological change is likely related to environmental factors like photoperiod and temperature. According to Ewing and Struik (1992), photoperiod and temperature are the major environmental factors that influence the growth of potato. Reduction in vegetative growth, early tuberization and senescence are the main responses of potato to short day conditions (Maris 1964; Haverkort 1990; Van Dam et al. 1996).

The late maturity group of cultivars had higher values for AUC and TYPP in DebreTabor compared to early and intermediate groups, but in Injibara the effect of maturity was different. The late maturity group had higher AUC values compared to the early and intermediate group but there was no visible difference in tuber yield, which may indicate that radiation use efficiency (RUE) of the late cultivars in this location was lower compared to the early and intermediate cultivars. The reason for the lower RUE of the later maturing cultivars especially at Injibara is not known. The soil of Injibara is very strongly acidic with $\mathrm{pH}$ value 4.8 and the average night temperature is low $\left(8^{\circ} \mathrm{C}\right)$ compared to Debre-Tabor with $\mathrm{pH}$ value 5.2 and average night temperature of $12^{\circ} \mathrm{C}$. Okazawa (1967) reported that low pH inhibited lateral shoot growth and retarded tuberization. According to the author, in potato plants, enzymes like amylase and phosphorylase which are responsible for the carbohydrate metabolism would play an important role in tuber formation and the optimum $\mathrm{pH}$ value of these enzymes is between 6.0 and 7.0. The low soil $\mathrm{pH}$ value may therefore have affected the tuber yield of potato cultivars especially in Injibara.

The effect of $\mathrm{N}$ level on canopy parameters was only significant for Vmax, AUC, $\mathrm{AP} 1, \mathrm{AP} 2$ and AP3. However, regardless of the effect of $\mathrm{N}$ levels, there was a difference among genotypes in growth phase duration; time to reach maximum canopy cover ( $\mathrm{t} 1$ ) was relatively longer than duration of maintenance of maximum canopy $(\mathrm{t} 2-$ t1), and as a result area under the curve for growth phase one (AP1) was greater than the area for the maximum canopy maintenance phase (AP2). Conversely, Ospina et al. (2014) using similar genetic background genotypes under Dutch environmental conditions reported that high $\mathrm{N}$ increased $\mathrm{t} 2-\mathrm{t} 1$, and $\mathrm{t} 2 \mathrm{-t}$ l was longer than the time to reach maximum growth (t1). AP1 decreased due to this short duration of t1, and AP2 was increased due to long duration of $\mathrm{t} 2 \mathrm{-t} 1$. The reversed response of growth phases duration ( $\mathrm{t} 1$ and $\mathrm{t} 2 \mathrm{-t} 1$ ) between the two environments (tropical in our experiments, and temperate for Ospina et al. (2014)) may be related to the reduction in maturity time 
under tropical conditions: the genotypes matured on average in less than 70 days under Ethiopian condition, while in European conditions similar cultivars took more than 100 days to mature.

The tuber yield reduction due to low $\mathrm{N}$ availability was substantial and significant in both locations. Of the two tuber yield components, tuber number had a larger effect on total tuber yield than average tuber weight especially in Injibara, which indicates that tuber bulking is less affected than tuberization by limiting $\mathrm{N}$ conditions. Previous studies indicated that limited $\mathrm{N}$ availability prior to tuberization leads to low yield due to poor tuberization (Dubetz and Bole 1975; Roberts et al. 1982). The high values for TDM\% in Injibara may be related to the lower temperature at this location, because at low temperature competition between vegetative growth and tuber bulking is low, and there may not be high vegetative growth at the expense of tuber bulking, resulting in high TDM\%. According to Winkler (1971) and Ewing (1981), at low temperature there is high assimilate accumulation and slight transpiration and no considerable vegetative growth at the expense of tuber bulking.

In potato, genetic variation of NUE is largely explained by maturity type (TiemensHulscher et al. 2012; Ospina et al. 2014). In our study, high NUE values were recorded at low $\mathrm{N}$ for late maturing potato cultivars. A similar result was reported by others (Zvomuya and Rosen 2002; Zebarth et al. 2004b; Burns 2006; Khan et al. 2013; Ospina et al. 2014). The long vegetative period may be the cause of the strong relationship between NUE and late maturity as late maturing cultivars have more time to accumulate assimilates compared to early cultivars. In this study, some of the late maturing potato cultivars like Kuras, and Asterix from the Dutch and most Ethiopian cultivars had better NUE compared to the other Dutch cultivars irrespective of the environment and $\mathrm{N}$ levels, indicating a persistent inherent potential of these cultivars for high NUE under both low and high $\mathrm{N}$ conditions.

In the cluster analysis, most of the cultivars grouped in a single cluster (cluster I) at both $\mathrm{N}$ levels; $87 \%$ at low $\mathrm{N}$ and $65 \%$ at high $\mathrm{N}$ were grouped in cluster I, and four cultivars existed each as independent cluster (singleton cluster) at each $\mathrm{N}$ level. The clustering of most potato cultivars in one cluster (87\% at low $\mathrm{N}$ and $65 \%$ at high $\mathrm{N}$ ) implies that the diversity of the population or the compositional similarities between genotypes in the population was not proportionally distributed. Wide genetic distance was observed between singletons Zengena and V13 at low N and between cluster V and Agerie at high N. However, most contrasting cluster means with significant inter-cluster genetic distance were present between cluster II and Zengena at low N, and cluster VII and Berber at high $\mathrm{N}$ for traits like days to maturity, NUE, TYPP and AUC, indicating selection of parents for hybridization from these paired clusters/cultivars at the respective $\mathrm{N}$ levels will be expected to give suitable segregation for those traits.

Coefficients of variation (PCV and GCV) measure the magnitude of variation present in a population. The results in this study revealed that estimates of PCV were quite close to the estimates of GCV for all measured traits over treatments at each location, indicating that the environment had a negligible effect on the variance of traits. Similarly, Gopal (1999) using clones from Indian potato breeding programmes in the Indian autumn and spring production season, and Baye et al. (2005) using CIPsourced Ethiopian breeding clones in the rain fed production season, reported high PCV and GCV values for plant height, tuber yield, average tuber weight and tuber number, which confirms that the genetic effect is consistent for the variation of these 
traits in different testing materials and environments. The small contribution of the environment to the total variation of the traits compared to the contribution of the genetic component indicates that the traits are heritable and suitable for selection. However, the environmental variance contributed a bit more to phenotypic variance at low $\mathrm{N}$ than at high $\mathrm{N}$. High $\mathrm{N}$ input may mask soil heterogeneity more than low $\mathrm{N}$ input, and as a result environmental variance was higher at low $\mathrm{N}$ than at high $\mathrm{N}$ supply (Bertin and Gallais 2001; Presterl et al. 2003).

The result of $h^{2}$ estimates, with the exception of Vmax and TDM\% at low $\mathrm{N}$ and NUE at both $\mathrm{N}$ levels which exhibited medium $h^{2}$ in Injibara, was high for all traits at both $\mathrm{N}$ levels and in both locations, demonstrating the suitability of these characters for genetic improvement through selection. Similar results were reported in several other studies (Chaudhary 1985; Desai and Jaiminis 1997; Baye et al. 2005; Regassa and Basavaraj 2005) and this similarity of heritability estimates in different testing environments and materials for plant height, tuber yield, average tuber weight and tuber number suggests that these traits can be used for selection and improvement in a variety of environments.

In this study, all traits showed high GA\% accompanied with high $h^{2}$, except for chlorophyll content and days to maturity with low to medium genetic advance values across N levels and locations. As Johnson et al. (1955) stated, the estimates of GA\% are more valuable as a means of selection when considered jointly with the estimates of $h^{2}$. In our study, ATW, TNPP, and AUC showed consistently high $h^{2}$ and GA\% values across treatments and locations. Thus, clonal selection can be based on these traits and their phenotypic expression and these are good indicators to use these traits for indirect selection to improve NUE.

The direct effect of TDM\% and TNPP in the path analysis and their indirect effects via DTM and AUC were substantial, indicating that direct selection of these traits can give satisfactory gain in NUE. However, DTM and AUC had a strong positive correlation with NUE and considerable indirect effect via TDM\% and TNPP, while their direct contributions to NUE variation were minor. In this situation the best strategy, according to Neder et al. (2013), should be the simultaneous selection of traits, targeting those with significant indirect effects. This can be checked through the predicted response to combined selection using an index (Wricke and Weber 1986). The over-location residual effect (R) of N levels ranged from 0.09 to 0.17 , indicating that more than $83 \%$ of the variation in NUE was contributed by the nine traits studied in the path analysis. This residual effect towards NUE in the present study may be due to other traits that were not included in this study, environmental factors, or sampling errors (Sengupta and Karatia 1971).

In summary, our study suggests that the Ethiopian potato cultivars and potato cultivars from the North-western European gene pool can be exploited for NUE improvement through improving and pyramiding of component traits such as TNPP, AUC, DTM, TDM\% and ATW. However, multi-environment trials may be required to use these traits for NUE indirect selection.

Acknowledgments The authors gratefully acknowledge the HZPC Holland BV for providing planting materials. The view expressed in this paper is neither of NUFFIC nor the HZPC Holland BV, rather it is the sole responsibility of the Authors.

Funding Information Netherlands fellowship programme (NUFFIC) for funded this work. 
Open Access This article is distributed under the terms of the Creative Commons Attribution 4.0 International License (http://creativecommons.org/licenses/by/4.0/), which permits unrestricted use, distribution, and reproduction in any medium, provided you give appropriate credit to the original author(s) and the source, provide a link to the Creative Commons license, and indicate if changes were made.

\section{References}

Bänzinger M, Cooper M (2001) Breeding for low input conditions and consequences for participatory plant breeding: examples from tropical maize and wheat. Euphytica 122:503-519

Baye BG, Ravishankar H, Singh HA (2005) Variability and association of tuber yield and related traits in potato. Ethiopian J Agri Sc 18:103-121

Bertin P, Gallais A (2001) Physiological and genetic basis of nitrogen use efficiency in maize. I Agro-Physiol Results Maydica 45:53-66

Bradshaw JE (2009) A genetic perspective on yield plateau in potato. Potato J 36:79-94

Burns IG (2006). Assessing N fertilizer requirements and the reliability of different recommendation systems. Acta Hort. pp. 35-48.

Burton GW, Devane EH (1953) Estimation of heritability in tall Festuca (Festuca arundinacea) from replicated clonal material. Agron J 45:478-481

Chaudhary SK (1985) Variability for some quantitative characters in potato. Crop Improv 12:179-199

Desai NC, Jaiminis N (1997) Genetic variability, heritability and genetic advance for yield in potato. Indian J Potato Assoc 24:52-58

Dewey DR, Lu KH (1959) A correlation and path co-efficient analysis of components of crested wheat grass seed production. Agron J 51:515-518

Dubetz S, Bole JB (1975) Effect of nitrogen, phosphorus, and potassium fertilizers on yield components and specific gravity of potatoes. Am Potato J 52:399-405

Dudley JW, Moll RH (1969) Interpretation and use of estimates of heritability and genetic variance in plant breeding 1. Crop Sci 9:257

Errebhi M, Rosen CJ, Lauer FI, Martin MW, Bamberg JB (1999) Evaluation of tuber bearing solanium species for nitrogen use efficiency and biomass partitioning. Am J Potato Res 76:143-151

Ewing EE (1981) Heat stress and the tuberization stimulus. Am Potato J 58:31-49

Ewing EE, Struik PC (1992) Tuber formation in potato: induction, initiation, and growth. Hortic Rev 14:89198

Falconer DS, Mackay TFC (1996) Introduction to quantitative genetics, 4th edn. Longman, Harlow

FAO ( Food and Agricultural organization) (2014) New -local climate estimator (LocClim) software and global climate database, available at: http://www.fao.org/NR/climpag/pub/en3_051002_en.asp

Flessa H, Ruser R, Schilling R, Lotfied N, Munch JC, Kaiser EA, Beese F (2002) $\mathrm{N}_{2} \mathrm{O}$ and $\mathrm{CH}_{4}$ fluxes in potato fields: automated measurement, management effects and temporal variation. Geoderma 105:307325

Gopal J (1999) Genetic parameters and character association for clonal selection in potato breeding programs. Agronomie 19:531-539

Haverkort AJ (1990) Ecology of potato cropping systems in relation to latitude and altitude. Agric Syst 32: $251-272$

Hill AR (1986) Nitrate and chloride distribution and balance under continuous potato cropping. Agric Ecosyst Environ 15:267-280

Hodge A, Robinson D, Fitter A (2000) Are microorganisms more effective than plants at competing for nitrogen? Trends Plant Sci 5:304-308

Johnson HW, Robinson HF, Comstock RE (1955) Genotypic and phenotypic correlations in soybeans and their implication in selection. Agron J 47:477-483

Khan MS (2012) Assessing genetic variation in growth and development of potato. $\mathrm{PhD}$ Thesis Wageningen University, Wageningen

Khan MS, Van Eck HJ, Struik PC (2013) Model-based evaluation of maturity type of potato using a diverse set of standard cultivars and a segregating diploid population. Potato Res 56:127-146

Kleinkopf GE, Westermann DT, Wille MJ, Kleinschmidt GD (1987) Specific gravity of Russet Burbank potatoes. Am Potato J 64:579-587

Lafitte HR, Edmeades GO (1994) Improvement for tolerance to low soil nitrogen in tropical maize III. Variation in yield across environments. Field Crops Res 39:27-38 
Lal GS, Bhaderiya VS, Singh AK (1997) Genetic association and path analysis in elite lines of sunflower. Crop Res Hisar 13:631-634

Mahalanobis PC (1936) On the generalized distance in statistics. Proc Natl Sci India B 2:49-55

Maris B (1964) Studies concerning the relationship between plant height of potatoes in the seedling year and maturity in the clonal generations. Euphytica 13:130-138

Moll RH, Kamprath EJ, Jackson WA (1982) Analysis and Interpretation of Factors Which Contribute to Efficiency of Nitrogen Utilization. Agron J 74(3):562-564

Murphy HJ, Goven MJ (1959) Nitrogen, spuds and specific gravity. Maine Farm Res 7(1): 21-24

Neder DG, da Costa FR, Edvan RL, Filho LT (2013) Correlations and path analysis of morphological and yield traits of cactus pear accessions. Crop Breeding Appl Biotech 13:203-207

Neele AEF, Nab HJ, Louwes KK (1991) Identification of superior parents in a potato breeding program. Theor Appl Genet 82:264-272

Nyquist WE (1991) Estimation of heritability and prediction of selection response in plant populations. Crit Rev Plant Sci 10:235-322

Okazawa Y (1967) Physiological studies on the tuberization of potato plants. J Fac Agri Hokkaido Univ Sapporo 55:Pt.3

Ospina CA, Lammerts van Bueren ET, Allefs JJJM, Engel B, van der Putten PEL, van der Linden CG, Struik PC (2014) Diversity of crop development traits and nitrogen use efficiency among potato cultivars grown under contrasting nitrogen regimes. Euphytica 199:13-29. https://oi.org/10.1007/s10681-014-1203-4

Presterl T, Seitz G, Landbeck M, Thiemt EM, Schmidt W, Geiger HH (2003) Improving nitrogen use efficiency in European maize: estimation of quantitative genetic parameters. Crop Sci 43:1259-1265

Regassa D, Basavaraj N (2005) Genetic variability studies in potato (Solanum tuberosum L.) Karnataka. J Agric Sci 18(1):87-90

Richards JE, Milburn PH, MacLean AA, Demerchant G (1990) Intensive potato production effects on nitrateN concentrations of rural New Brunswick well water. Can Agric Eng 32:189-196

Roberts S, Weaver WH, Phelps JP (1982) Effect of rate and time of fertilization on nitrogen and yield of Russet Burbank potatoes under center pivot irrigation. Am Potato J 59:77-96

Sengupta K, Karatia AS (1971) Path co-efficients analysis for some characters in soybean. Indian J Genet 31: 290-295

Thompson JA, Nelson RL (1998) Core set of primers to evaluate genetic diversity in soybean. Crop Sci 38(5): 1356-1362

Tiemens-Hulscher M, Lammerts van Bueren ET, Hutten RCB (2012) Potato: improving organic cultivars including a participatory approach. In: Lammerts van Bueren ET, Myers JR (eds) Organic crop breeding. Wiley-Blackwell, Hoboken, pp 227-233

Van Dam J, Kooman PL, Struik PC (1996) Effect of temperature and photoperiod on early growth and final number of tubers in potato (Solanum tuberosum L). Potato Res 39:51-62

Vos J (1995) The effects of nitrogen supply and stem density on leaf attributes and stem branching in potato (Solanum tuberosum L.). Potato Res 38:271-279

Vos J (2009) Nitrogen responses and nitrogen management in potato. Potato Res 52:305-317

Winkler E (1971) Potato cultivation in Tyrol. II. Photosynthetic efficiency and respiration in different potato varieties. Potato Res 14:1-18

Wricke G, Weber WE (1986) Quantitative genetics and selection in plant breeding. Walter de Gruyter, Berlin

Yin X, Goudriaan J, Lantinga EA, Vos J, Spiertz HJ (2003) A flexible sigmoid function of determinate growth. Ann Bot 91(3):361-371

Zebarth BJ, Tai G, Tarn R, de Jong H, Milburn PH (2004a) Nitrogen use efficiency characteristics of commercial potato cultivars. Can J Plant Sci 84:589-598

Zebarth BJ, Leclerc Y, Moreau G (2004b) Rate and timing of nitrogen fertilization of Russet Burbank potato: nitrogen use efficiency. Can J Plant Sci 84:845-854

Zvomuya F, Rosen CJ (2002) Biomass partitioning and nitrogen use efficiency of 'Superior' potato following genetic transformation for resistance to Colorado beetle. J Am Soc Hortic Sci 127:703-709

Publisher's Note Springer Nature remains neutral with regard to jurisdictional claims in published maps and institutional affiliations. 


\section{Affiliations}

\section{Baye Berihun Getahun ${ }^{1,2}$ - Molla Mekonen Kassie ${ }^{2}$.}

Richard G. F. Visser ${ }^{1} \cdot$ C. Gerard van der Linden ${ }^{1}$

1 Plant Breeding, Wageningen University and Research, P.O. Box 386, 6700 AJ Wageningen, The Netherlands

2 Baye Berihun Getahun, Molla Mekonen Kassie, Amhara Regional Agricultural Research Institute, ARARI, P.O. Box. 527, Bahirdar, Ethiopia 